\title{
PENGARUH UNSUR SILIKON PADA ALUMINIUM ALLOY (Al - Si) TERHADAP SIFAT MEKANIS DAN STRUKTUR MIKRO
}

\author{
Ratih Ponco K.S., Erwin Siahaan dan Steven Darmawan \\ Jurusan Teknik Mesin, Fakultas Teknik Universitas Tarumanagara
}

\begin{abstract}
Aluminum is one of type in material non-ferrous metals are frequently and widely used in fields of application in industry. One application that performed in the industrial world, namely Aluminum Silicon (AlSi) which are used for the motor piston components. To get better mechanical properties then the integration of Aluminum Silicon research done by arranging the variety of Si element content on a percentage of 6,8 , and $10 \%$ Si.Testing is done by using a blend of $10 \%$ genuine with further lowering the Si content to reach $6 \%$ and $8 \%$ by adding pure aluminum. The test showed that the level of harness decreased $12,5 \%$ and also the ability of toughness decreased by $4 \%$. Observation show that the microstructure is relatively homogeneous and there is a dominant form of micro-structure of pure Al and several dendrites CuAl.
\end{abstract}

Keywords: Aluminuium, Al-Si, Silicon, Impact test, Hardness test, microsturcturw observation

\begin{abstract}
Abstrak: Aluminium merupakan salah satu jenis material logam non-ferrous yang sering dan banyak digunakan dalam bidang aplikasi di dunia industri. Salah satu aplikasi yang dilakukan pada dunia industri yaitu logam aluminium Aluminium Silikon (AlSi) digunakan untuk komponen piston motor. Untuk mendapatkan sifat mekanis yang lebih baik maka pada penelitian dilakukan pemaduan Aluminium Silikon dengan mengatur variasai kandungan unsur Si pada persenatse 6, 8 dan 10\% Si. Pengujian dilakukan dengan menggunakan paduan 10\% AlSi dengan selanjutnya menurunkan kandungan Si untuk mencapai $6 \%$ dan $8 \%$ dengan menambah Aluminium murni. Dari pengujian diperoleh bahwa tingkat kekerasan menurun $12.5 \%$ dan juga kemampuan ketangguhan menurun 4\%.Pengamatan sruktur mikro memperlihatkan bahwa yang bersifat relative homogen dan bentuk struktur mikro terdapat dominan Al murni dan juga bebrapa dendrite, $\mathrm{Cu}_{2} \mathrm{Al}$.
\end{abstract}

Kata Kunci: Aluminium, Al - Si, silicon, uji impact, uji kekerasan, pengamatan struktur mikro

\section{PENDAHULUAN}

Logam umumnya digunakan dalam industri karena memiliki beberapa keunggulan seperti kuat, mudah diolah, tidak mudah rusak dan memiliki unsur pakai yang cukup lama, selain itu, logam juga termasuk sumber daya alam yang tidak dapat diperbarui. Salah satu logam yang digunakan adalah aluminium. Aluminium adalah logam yang tidak termasuk dalam jenis logam berat. Penelitian ini mencakup perbedaan paduan silikon (\% berat) pada aluminium yang dapat meningkatkan sifat mekanis dan struktur mikro.

Akhir-akhir ini, para peneliti berusaha untuk menghasilkan bahan yang memiliki ketangguhan yang sama walaupun dari bahan daur ulang. Campuran silicon dibedakan jumlah campurannya dengan satuan \% berat. Penelitian ini dilakukan untuk mengetahui sifat mekanis dan struktur mikro terhadap jumlah campuran silikon pada aluminium dengan peleburan di dalam crucible.

\section{METODE PENELITIAN}

Metode penelitian dibuat untuk menyusun langkah-langkah yang akan dilakukan dalam melakukan penelitian sehingga penelitian berjalan secara sistematis dan terarah. Adapun langkahlangkah yang dilakukan dapat dilihat dalam Gambar 1 di bawah ini. Setelah pengujian dilakukan, data-data yang didapat akan dianalisa lebih lanjut. Tahap terakhir adalah kesimpulan dan saran.

Prosedur penelitian meliputi beberapa tahap, yaitu:

\section{a. Menyiapkan material}

Material yang disiapkan terdiri dari dua jenis yaitu aluminium murni (ingot) dan aluminium ADC12. Untuk mendapatkan Al-Si 6\% paduan 142,642gr ADC12, 95,498gr aluminium murni. 
Untuk mendapatkan Al-Si 8\% paduan 190,194gr ADC12, 47,946gr aluminium murni. Untuk mendapatkan Al-Si 10\% paduan 238,14gr, 0gr aluminium murni.

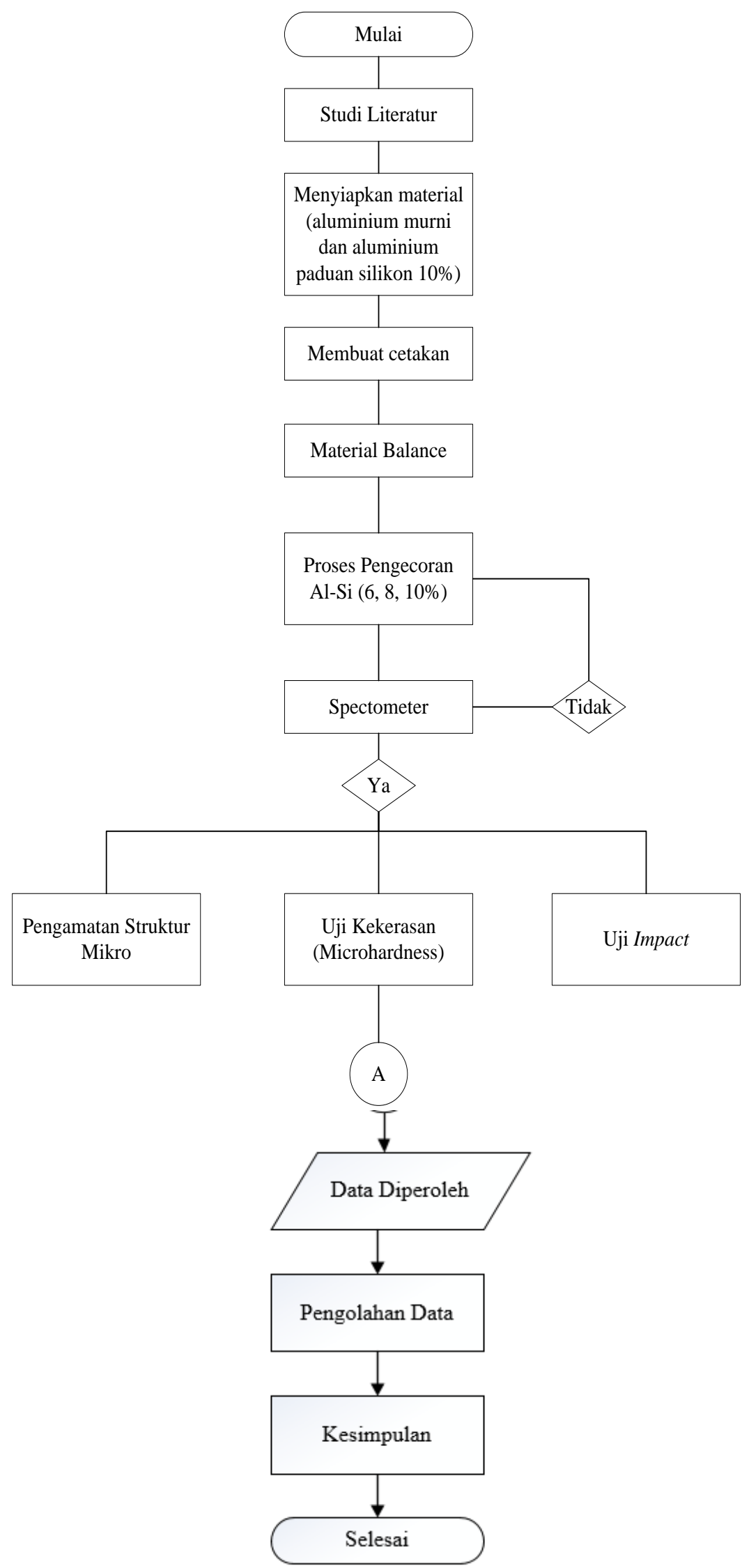

Gambar 1. Diagram alir metode penelitian 

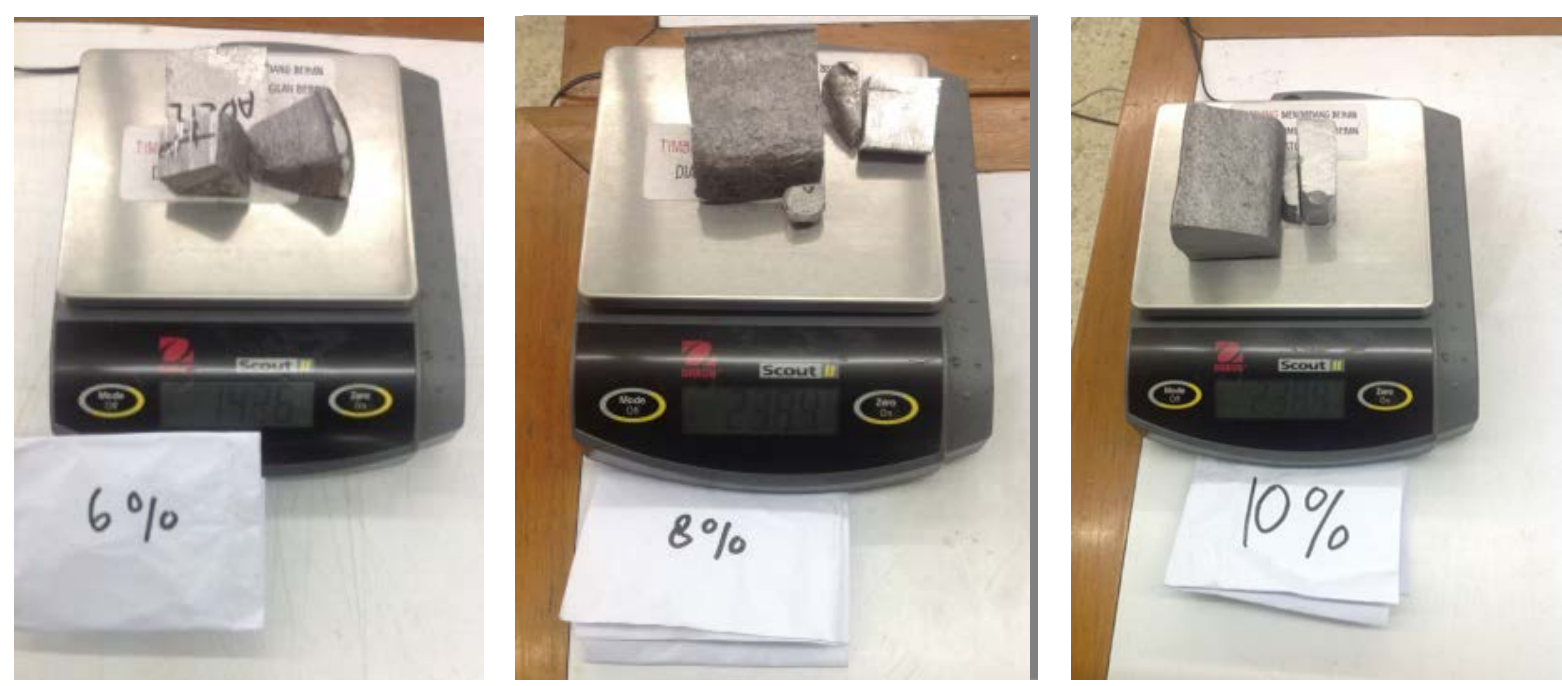

Gambar 2. Persiapan material Al-Si 6\%, Al-Si 8\%, Al-Si 10\%

\section{b. Proses pengecoran}

Proses pengecoran dengan menggunakan tungku dan dicetak dengan cetakan logam. Peleburan sampai suhu $800^{\circ} \mathrm{C}$ yang ditunjukan thermocouple kemudian dicetak ke dalam cetakan dan tunggu sampai bahan membeku.

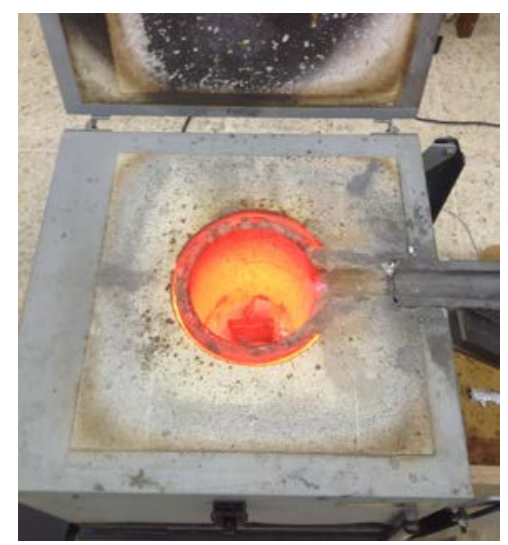

Gambar 3. Proses pengecoran dengan tungku

\section{c. Spectrometer}

Bahan yang telah dicor akan dilakukan pengujian komposisi kimia agar hasil kandungan silikon sesuai dengan bahan pengujian yaitu 6\%, 8\%, 10\% silikon. Pengujian dilakukan dengan mesin Optical Emission Spectrometer.

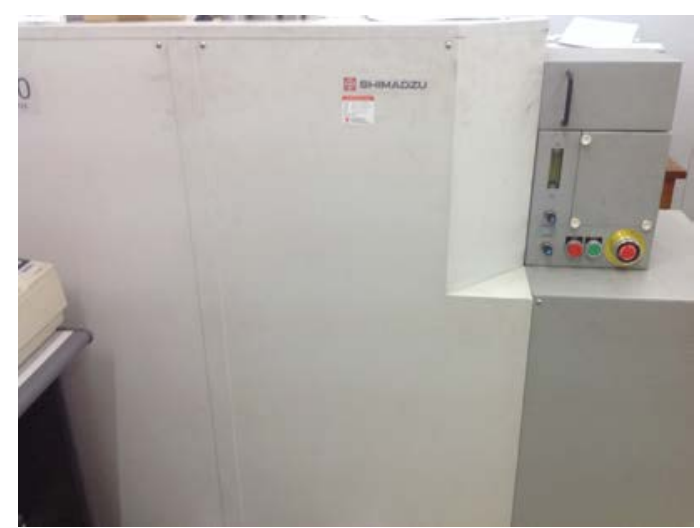

Gambar 4. Pengujian komposisi kimia 


\section{d. Pembentukan spesimen}

Pembentukan spesimen untuk pengujian Impact dengan metode charpy, kekerasan (microhardness), pengamatan struktur mikro.<smiles>[141In]</smiles>

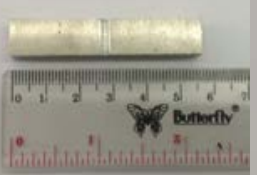

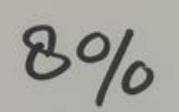

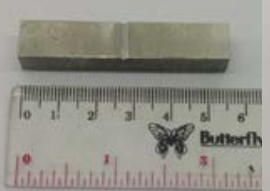

$10 \%$

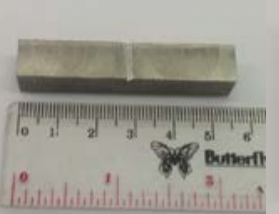

$6 \%$

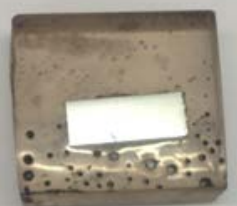

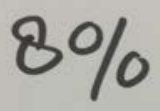

$10 \%$

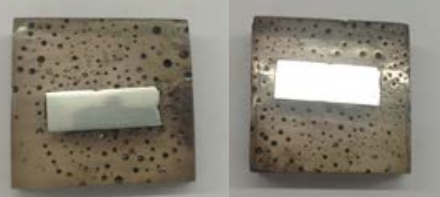

Gambar 5. Spesimen pengujian Impact, kekerasan, pengamatan struktur mikro

\section{e. Pengujian Impact}

Uji impak digunakan dalam menentukan kecenderungan material untuk rapuh atau ulet berdasarkan sifat ketangguhannya. Specimen yang akan diuji di bentuk dengan menggunakan proses permesinan CNC, dengan dimensi $10 \mathrm{~mm} \times 10 \mathrm{~mm} \times 55 \mathrm{~mm}$. Uji impact yang dilakukan menggunakan standard ASTM E23.

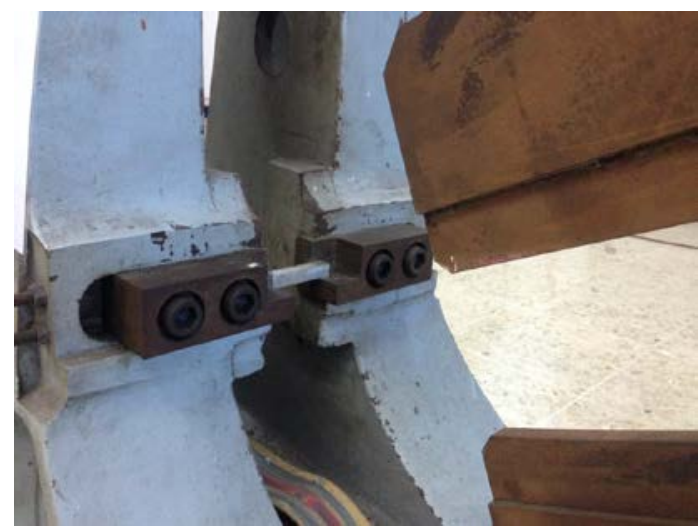

Gambar 6. Pengujian Impact

\section{f. Pengujian kekerasan (Microhardness)}

Micro hardness merupakan pengujian yang cocok untuk pengujian material yang nilai kekerasannya rendah. Metode ini biasanya digunakan untuk mengukur material yang getas seperti keramik dan hanya terbatas pada daerah yang kecil.

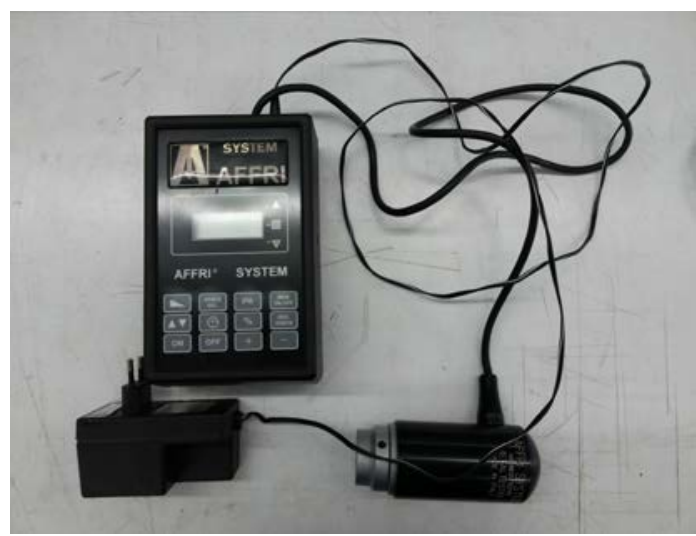

Gambar 7. Pengujian kekerasan (microhardness) 


\section{g. Pengamatan struktur mikro}

Pengamatan ini dilakukan dengan menggunakan cairan etsa 0,5 HF agar gambar struktur dapat terlihat dengan jelas. Pengamatan struktur mikro dengan perbesaran 500x agar terlihat besar dan sebar butir dan bentuk dendrit.

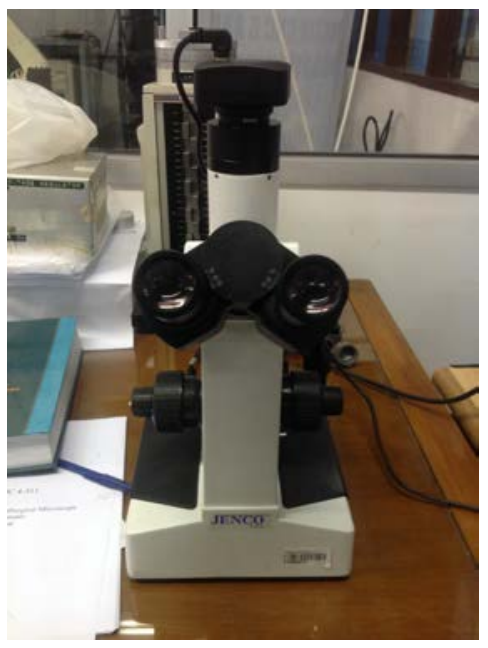

Gambar 8. Pengamatan struktur mikro

HASIL DAN PEMBAHASAN

a. Pembahasan hasil pengujian Impact

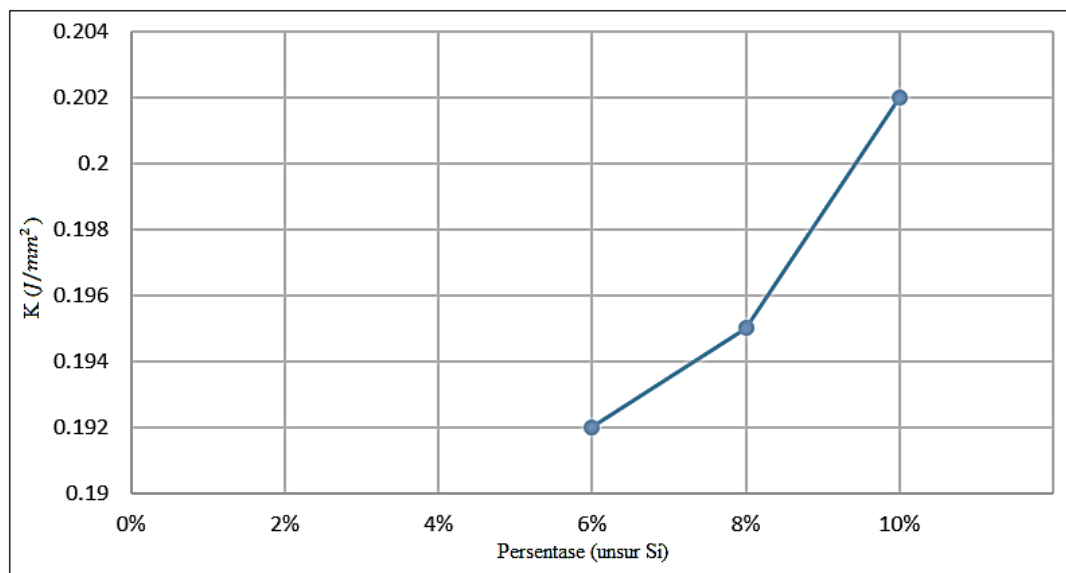

Gambar 9. Grafik pengujian Impact perbandingan K dengan presentase Silicon pada Aluminium

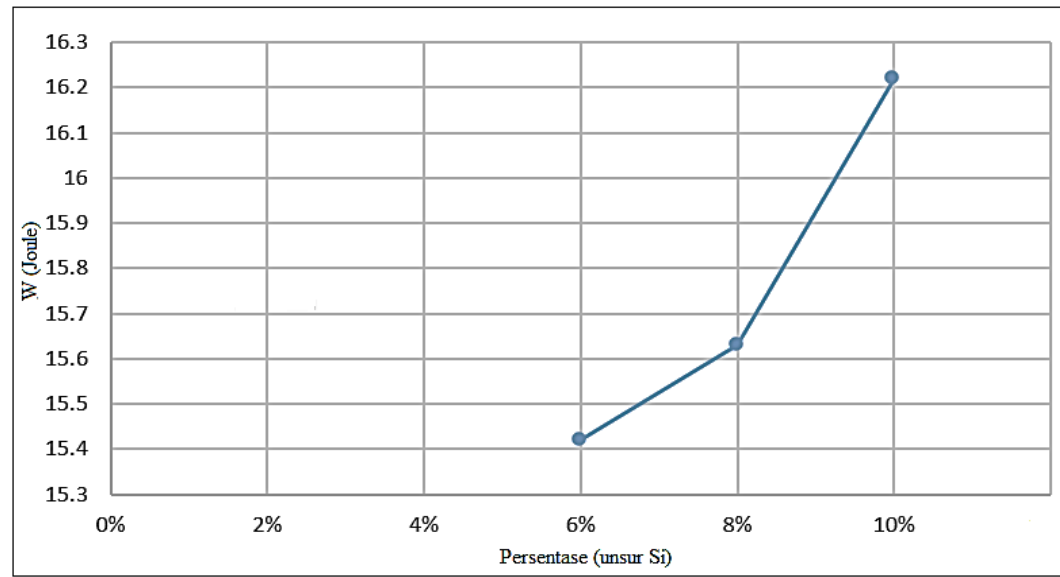

Gambar 10. Grafik pengujian Impact perbandingan W dengan presentase Silicon pada Aluminium 


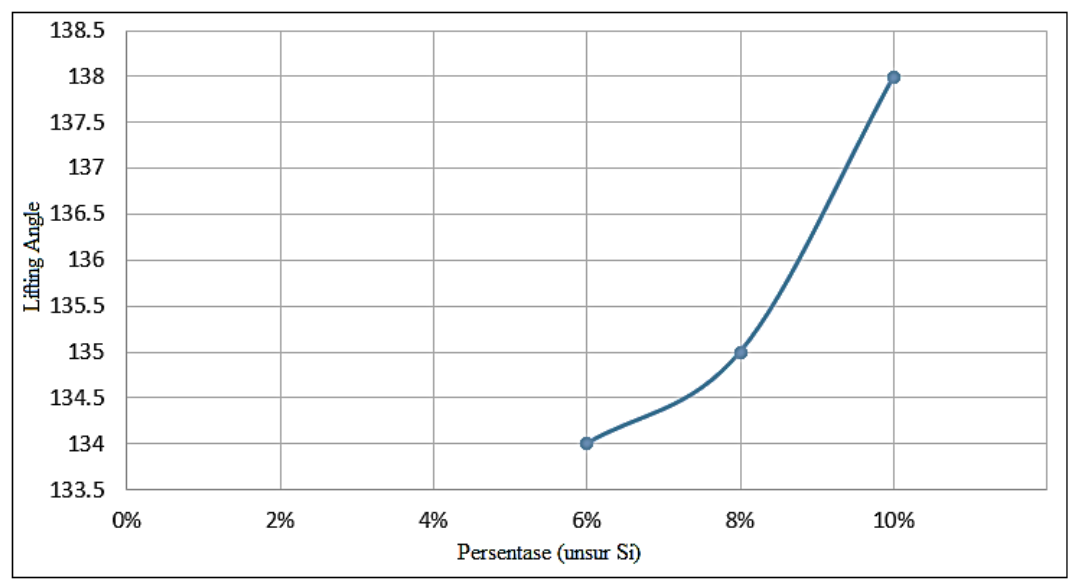

Gambar 11. Grafik pengujian Impact perbandingan Sudut dengan persentase Silicon pada Aluminium

Dari hasil uji impact diketahui energi serap Aluminium yang memiliki paduan silicon lebih banyak akan semakin besar. Begitu juga dengan Harga Impact berbanding semakin besar presentase Silicon yang dimiliki oleh aluminium maka semakin besar pula harga impact yang dihasilkan. Apabila di tinjau dari jenis patahan, aluminium silicon mengindikasikan aluminium jenis getas, karena hasil patahannya berwarna mengkilat dan bekas patahan yang cenderung merata.

b. Pembahasan hasil pengujian kekerasan (microhardness)

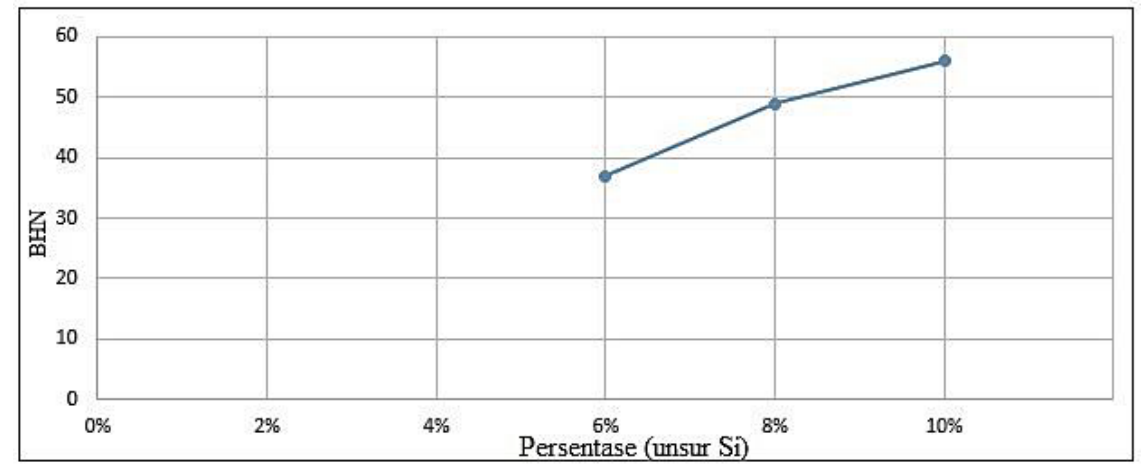

Gambar 12. Grafik perbandingan kekerasan material Al - Si (6, 8, 10\%)

Berdasarkan data hasil pengujian kekerasan metode Brinnel diketahui bahwa kekuatan rata rata aluminium - silicon yang paling besar adalah $56 \mathrm{HRB}$, dengan kadar silicon 10\%. Hal ini disebabkan oleh terjadinya penyebaran Kristal halus dan homongen dari unsur silicon yang semakin banyak pada Aluminium paduan, karena presentase silicon yang lebih besar.

c. Pembahasan hasil pengamatan struktur mikro

Dari hasil pengamatan Struktur Mikro Al - Si 6\% dengan pembesaran 500x bagian dari struktur yang tidak terisi atau dialiri silikon eutektik akan muncul sebagai porositas penyusutan. Kekosongan ini disebabkan oleh 1) silikon eutektik yang terbentuk sedikit (sehingga tidak mampu mengisi semua rongga yang ada), 2) proses pembekuan Al-Si cair yang terjadi dalam waktu yang bersamaan, sehingga proses feeding saat proses pembekuan tidak terjadi. Opsi ini memungkinkan untuk terjadinya porositas penyusutan yang akan menjadi inisial retak. Selain itu temperatur tuang dan cetakan yang tinggi akan mengakibatkan pembekuan lambat, sehingga tersedia tegangan regangan penyusutan dan kontraksi panas yang besar untuk perkembangan retak. 


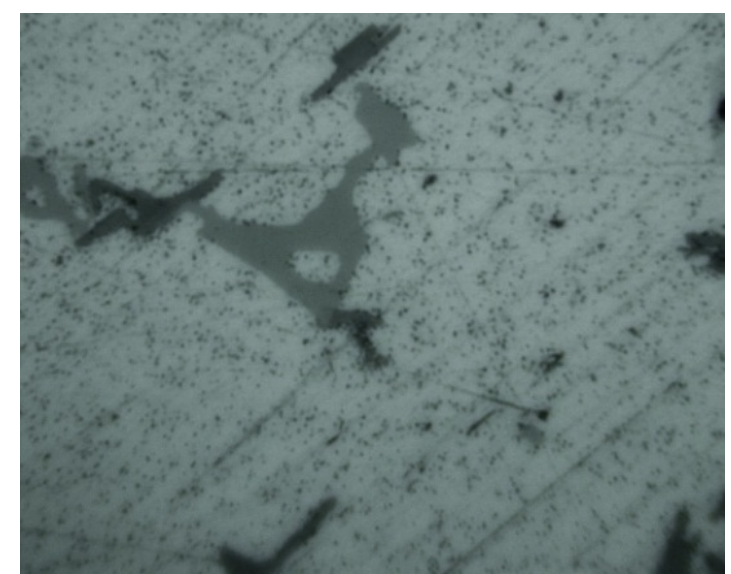

Gambar 13. Pengamatan Struktur Mikrol Al - Si (6\%)

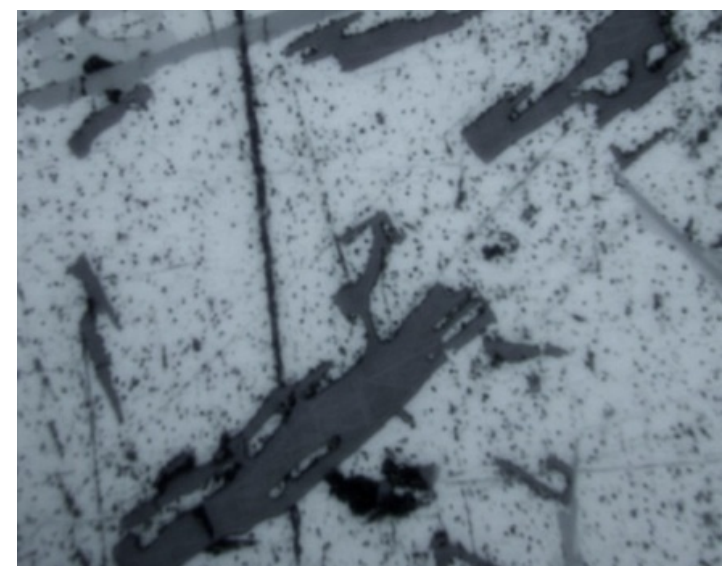

Gambar 14. Pengamatan Struktur Mikro Al - Si 8\% dengan pembesaran 500x.

Pola nodles silikon (berwarna hitam lebih gelap) dalam matriks aluminium yang membentuk dendrit-dendrit panjang tersebar merata, teramati pada permukaan produk. Tidak ditemukan porositas dipermukaan produk. Apabila terdapat porositas, hal ini disebabkan oleh dua jenis yaitu porositas penyusutan dengan bentuk tidak teratur dan porositas gas berbentuk lingkaran. Namun porositas ditinjau dari ukuran ada dua, yaitu porositas makro dan mikro. Porositas penyusutan dengan bentuk tidak teratur ini disebabkan oleh ketida kmampuan/kekurangan silikon eutektik untuk menetralkan penyusutan dan kontraksi panas (deformasi) selama proses pembekuan. Selama pembekuan terjadi proses feeding dimana silikon eutektik yang terbentuk akan melingkungi butir dendrit.

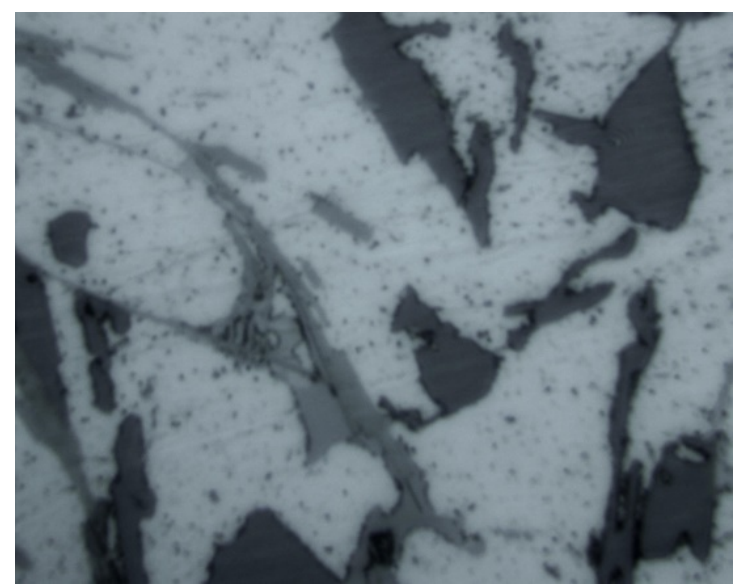

Gambar 15.Pengamatan Struktur Mikro Al - Si 10\% dengan pembesaran 500x 
Berdasarkan hasil pengujian struktur mikro pada aluminium - silicon (6, 8, 10\%) memiliki karakteristik sebagai berikut :

1. Fasa Al (berwarna terang) adalah larutan padat primer.

2. Fasa Si (berwarna gelap) pada umumnya akan dapat meningkatkan tingkat kekerasan dan memperlambat laju korosi.

\section{KESIMPULAN}

Berdasarkan penelitian yang telah dilakukan dapat ditarik kesimpulan, yaitu Dengan penambahan unsur silicon pada paduan AlSi maka didapat hasil nilai ketangguhan impactnya ikut bertambah. Untuk pengujian kekerasan mikro, hasil yang didapatkan adalah sesuai dengan penambahan unsur silicon pada paduan AlSi maka terjadi juga penambahan tingkat kekerasan. Dari pengamatan pada ketiga spesimen, terbentuk beberapa fasa yang dapat diambil, antara lain : fasa Aluminium berwarna terang dan fasa Silicon berwarna gelap. Dari penelitian yang dilakukan dengan variasi komposisi 6\%, 8\%, 10\% pada paduan AlSi maka hasil yang didapat adalah nilai ketangguhan berbanding tegak lurus dengan jumlah presentase silicon.

\section{DAFTAR PUSTAKA}

[1]. Alwi,Ibrahim. 1994. Lingkungan Korosi Aqueous. Bandung : ITB

[2]. Harpit,Boy.2012.Meningkatkan Sifat Mekanis Aluminium Komersil untuk Bahan Konstruksi Atap dengan Metode Accumulative Roll-Bonding.USU

[3]. Jurnal Imiah Teknik Mesin, Vol. 1, No. 2, Agustus 2013 , Universitas Islam 45, Bekasi

[4]. Setiawan,Hera. Pengujian kekuatan Tarik, kekerasan, dan struktur mikro produk cor propeller kuningan.2013

[5]. Ika,Wahyuni. Uji Kekerasan Material dengan Metode Vickers

[6]. Pembuatan safety bahel motor xxxberbahan ADC12 dengan system cor pasir cetak $\mathrm{Co}_{2}$.2011.Universitas Gunadarma

[7]. Annual Hand Book ASTM B577. Standard Test Methods of Tension Testing Wrought and Cast Aluminum- and MagnesiumAlloy Products1

[8]. Annual Hand Book ASTM E1251 - 11 Standard Test Method for Analysis of Aluminium and Aluminum Alloys by Spark Atomic Emission Spectrometry.

[9]. Annual Hand Book ASTM E 3 - 01 Standard Guide for Preparation of Metallographic Specimens1. 